\title{
MODEL PEMANFAATAN CAGAR BUDAYA UNTUK KESEJAHTERAAN MASYARAKAT STUDI KASUS EVENT MALANG KEMBALI
}

\author{
BLASIUS SUPRAPTA \\ Jurusan Sejarah, Universitas Negeri Malang
}

\begin{abstract}
Abstrak: Perhelatan akbar Malang Kembali dapat dijadikan model tentang pemanfaatan bangunan cagar budaya untuk kesejahteraan masyarakat berbasis pada pelestarian serta penanaman kesadaran sejarah daerah. Langkah-langkah yang ditempuh yaitu melakukan kajian mendalam tentang bangunan-bangunan cagar budaya untuk mengungkap nilai sejarah, arsitektur dan kemudian mengkaitkannya dengan tradisi budaya yang masih berlanjut. Nilai-nilai sejarah dan arsitektur bangunan cagar budaya tersebut dikemas dalam kegiatan even hari jadi kota atau daerah yang berbasis pada pelestarian cagar budaya dan untuk membangkitkan emage pariwisata budaya. Untuk menunjang hal itu maka perlunya membangun museum daerah dan guide book pariwisata lintasan sejarah kota atau daerah.
\end{abstract}

Kata-kata kunci: bangunan cagar budaya, pelestarian, nilai sejarah

Abstract. The glorification of Malang Kembali can be used as a model on the utilization of heritage buildings for public welfare based on the preservation and cultivation of awareness of the area's history. Steps to be taken of deepest conduct studies on cultural heritage buildings to reveal the value of history, architecture and then link it to the cultural tradition that still continues. The values of the historical and architectural heritage building is packaged in activities even days so a city or area based on the preservation of cultural heritage and cultural tourism to generate emage. To support it, the necessity of building a regional museum and tourist guide book trajectories city or region.

Keywords: heritage buildings, preservation, the value of history

Pemanfaatan Cagar Budaya yang mengarah pada kegiatan pelestarian telah banyak digelorakan oleh beberapa negara termasuk Indonesia. Di China misalnya, pada tahun1985, di saat akan membangun rel kereta api antara Kota Beijing dengan Dataran Tinggi Tibet, mengalami kendala teknis. Kendala teknis yang dialami antara lain yaitu jalur kereta api yang direncanakan harus dibangun di kawasan padang rumput, terletak pada ketinggian $2.000 \mathrm{~m}$ di atas permukaan laut, sehubungan dengan hal ini, pada malam hari suhu udara di kawasan padan rumput tersebut dapat mencapai hingga - 50 ${ }^{\circ}$ C. Kondisi ekologi semacam ini, antara lain mengakibatkan struktur tanah yang akan dilewati jalur kereta api tersebut pada siang hari mengalami proses pemekaran atau memuai dan pada malam hari, pada saat suhu mencapai $-50^{\circ} \mathrm{C}$, struktur tanah mengalami penyusutan secara ekstrim. Berkaitan dengan hal itu, maka apabila dibangun jalur rel kereta api, maka rel akan bergerak setiap hari serta tidak stabil, sehingga tidak bisa dilalui kereta api. Namun berkat penemuan teknik konstruksi situs "kubur kuno" yakni kubur batu fase perkembangan megalitik di sekitar kawasan padang rumput tersebut, maka jalur kereta api Beijing - Dataran Tinggi Tibet, bisa dibangun dengan teknologi sederhana serta berbiaya murah dan cepat.

Konstruksi situs "kubur kuno" tersebut berupa dua gundukan tanah berbentuk melingkar dan bagian atas gundukan tersebut, ditutup dengan susunan konstruksi bebatuan kali, sehingga struktur bangunan "kubur kuno" tersebut dapat dimasukkan sebagai kubur batu fase perkembangan tradisi megalitik. Secara cermat, 
konstruksi batu-batu kali kubur batu tersebut diamati oleh tekno-arkeologi dan hasil pengamatan menunjukkan bahwa tanah gundukan yang ditutupi oleh susunan batu-batu kali tersebut tidak pernah mengalami penyusutan di malam hari dan tidak mengalami pengembangan atau memuai di siang hari, pada hal lokasi situs tersebut tidak begitu jauh dari kawasan padang rumput. Setelah diteliti secara cermat, diketahui bahwa konstruksi batu-batu kali tersebut sebagai faktor utama penghambat tidak berubahnya struktur tanah kubur batu tersebut. Salah satunya yaitu susunan batu-batu kali tersebut di siang hari menyerap panas matahari dan sebagai penghalang sinar matahari mengenai tanah gundukan, tanah gundukan tidak langsung terkena sinar matahari, sehingga kondisinya tidak mengalami pemekaran. Adapun di malam hari, susunan batu-batu kali tersebut di samping sebagai penyimpan panas sinar matahari, juga sebagai penghalang cuaca dingin, udara malam hari tidak langsung mengenai tanah, sehingga tanah gundukan kubur tersebut pada malam hari tidak mengalami penyusutan.

Berpijak pada hasil penelitian konstruksi kubur batu tersebut dapat disimpulkan bahwa struktur tanah di kawasan padang rumput tidak akan mengalami penyusutan serta pengembangan apabila di permukaan struktur tanah tersebut ditutupi atau dilapisi oleh susunan konstruksi batu-batu kali. Atas dasar hasil penelitian tersebut, maka untuk membangun rel kereta api yang melintasi kawasan padang rumput tersebut, maka konstruksi rel kereta api dibangun di atas lapisan struktur batu-batu kali seperti halnya konstruksi kubur batu, sehingga pembangunannya dapat diselesaikan secara cepat, murah serta tepat sasaran, dengan cara memanfaatkan teknologi teknologi "kubur kuno" tersebut. Inilah suatu gambaran nyata tentang pemanfaatan "Cagar Budaya" untuk kesejahteraan masyarakat bahwa teknologi kubur batu dapat diaplikasikan untuk membangun jalan kereta api (Kartasasmita, 1979: 56-71).
Dalam kaitannya dengan "alegori” atau contoh kasus tersebut di atas, maka dapat diketahui bahwa teknologi masa lalu yang berbasis pada penemuan teknologi "Cagar $\mathrm{Bu}$ daya", dan dikembangkan di masa kini, akan mendatangkan kemanfaatan yang luar biasa seperti halnya pembangunan jalur kereta api di China tersebut, sehingga bermanfaat bagi kesejahteraan masyarakat. Dalam hubungannya dengan hal ini, pada makalah ini akan dikemukakan tentang pemanfatan "Cagar Budaya" yakni Bangunan Indiis di Kota Malang, untuk kegiatan "Even Malang Kembali" yang telah secara nyata bermanfaat untuk kesejahteraan masyatakat. "Even Malang Kembali" telah dilakasanakan selama 7 (tujuh) kali berturutturut yakni dimulai pada 2006, 2007, 2008, 2009, 2010 serta 2011 dan diselengarakan setiap Bulan Mei pada tahun berjalan. Hal-hal yang menjadi dasar kegiatan "Even Malang Kembali" adalah sejarah lahir dan berkembangnya Kota Malang bebasis pada bangunan "Cagar Budaya" seperti bangunan-bangunan Indiis beserta seluk-beluknya, khususnya berkenaan dengan nilai penting dalam kaitannya penanda proses Perkembangan Kota Malang, nilai kesejarahan dan nilai arsitektur bangunan. Dalam makalah ini dibahas tentang (1) lintasan sejarah Kota Malang, (2) potentsi "Cagar Budaya" yakni bangunan Indiis dalam kaitannya dengan lahir serta berkembangnya Kota Malang, (3) model pemanfaatan "Cagar Budaya" yakni bangunan Indiis untuk kegiatan "Even Malang Kembali" dan (4) manfaat bangunan "Cagar Budaya" untuk kesejahteraan masyarakat.

\section{LINTASAN SEJARAH KOTAPRAJA MALANG}

Sejarah perkembangan Kotapraja Malang tidak dapat dipisahkan dari perkembangan sejarah dunia, salah satunya yaitu peristiwa Konvensi London tahun1814. Pada Konvensi London tahun1814, secara politis Indonesia 
dikembalikan lagi oleh Inggris kepada Belanda di bawah Komisaris Jenderal Baron van der Capelen (1819-1824). Pada masa jabatan Van der Capellen tersebut untuk pertama kalinya secara formal dibentuk pemerintahan karisidenan dan kabupaten di Tanah Jawa. Pembentukan karisidenan di Tanah Jawa, mengacu pada Keputusan Komisaris Jenderal Tgl. 9 Januari 1819 No.3 yang termuat dalam Staatblad 1819 No.16. Dalam surat keputusan tersebut, disebutkan bahwa pembentukan karesidenan di Tanah Jawa terbagi menjadi (1) Karisidenan Banten, (2) Jakarta, (3) Bogor, (4) Priangan, (4) Krawang, (5) Cirebon, (6) Tegal, (7) Pekalongan, (8) Semarang, (9)Kedu, (10) Yogyakarta, (11) Surakarta, (12) Jepara serta Juwana, (13) Surabaya, (14) Pasuruan, (15) Besuki, (16) Banyuwangi, (17) Madura serta Sumenep, (18) Rembang dan (19) Karisidenan Gresik.

Berdasarkan laporan Algemeen Jaarlijksoh Verslag tahun1923, diketahui bahwa Karisidenan Pasuruhan yang dibentuk berdasarkan Staatsblad 1919 No.16, terdiri atas 3 wilayah kapubaten yaitu Kabupaten Pasuruan, Kabupaten Bangil dan Kabupaten Malang, sehingga pembentukan Kabupaten Malang kemungkinan berlangsung antara tahun1819 dan 1823. Berdasarkan data "Detailed Settlement of the Residency of Malang, 1812", Kabupaten Malang terdiri atas 6 buah distrik (kawedanan) yakni (1) Kawedanan Kotta, (2) Kawedanan Karang Lo, (3) Kawedanan Pakis, (4) Kawedanan Gondang Legi, (5) Kawedanan Penanggunngan dan (6) Kawedanan Ngantang. Kampung-kampung yang masuk Kawedanan Kota antara lain kampung Kidul Pasar (Kidol Pasar), Talun (Tallon), Kauman (Kahooman), Ledok (Leddok), Padeyan (Padeyan), Klojen (Clojean), Lor Alun (Lor Alloon), Gadang (Geddong), Temenggungan (Tarmmengoohan), Poleyan (Palleyan), Jodipan (Joddepan), Kabalen (Kaballen) dan Kota Lama : Cooto Lawas (Peta Overzigtskaart en Bladwijzer van de Residentie Pasoeroean tahun1880, Peta
Topografi Malang 1914 dan Team Sejarah IKIP - Malang 1976: 60-61).

Dalam perkembangan selanjutnya, pada tahun1914, Kabupaten Malang mengalami perubahan penting yakni dengan ditetapkannya Kawedanan Kota Malang menjadi Kota Praja (Gemmente) dengan keputusan Saatsblad No.197, tgl. 25 Maret 1914 dan keputusan ini mulai berlaku pada tgl. 1 April 1914. Dengan demikian Kabupaten Malang mulai tahun 1914 terdiri atas 7 wilayah kawedanan yaitu Kawedanan Penanggungan, Ngantang, Sengguruh, Turen, Gondang Legi, Pakis dan Kawedanan Karang Lo. Pejabat Gemmente : Kota Praja Malang, pertama dijabat oleh Burgemeester Bussemaker yakni pada 5 Juli 1919 - Februari 1929 (Leimpt, 1939). Pada tahun1914 jumlah penduduk Kota Praja Malang mencapai sekitar 40.000 orang terbagi atas 33.500 orang pribumi Indonesia, 2.500 Belanda dan 4.000 Tionghoa serta Arab (Stadsgemeente Malang 1914-1939, Gdenkboek 1939). Tempat tinggal yang diminati orang-orang Belanda yaitu di sebelah utara alun-alun, adapun penduduk Tionghoa mengelompok di sebelah timur-laut alun-alun dan penduduk Arab di sebelah selatan alun-alun. Penduduk pribumi Indonesia menyebar di seluruh kota terutama di sekitar alun-alun, sekitar pasar dan di wilayah Kabupaten Malang.

Pemerintahan kotapraja, mula-mula berada di tangan Dewan Kotapraja yang anggotaanggotanya ditunjuk oleh Asiten Residen Malang. Anggota mayoritas Dewan Kotapraja dijabat orang-orang Belanda dan pada tahun1919 Kotapraja Malang mendapatkan walikota pertama yaitu Burgemeester Bussemaker. Di bawah pemerintahan kotapraja, Malang berkembang pesat apalagi didukung dengan berkembang pesatnya tanaman kopi serta tebu di daerah Kabupaten Malang, sehingga di pusat kota banyak berdiri gedung-gedung pemerintahan, sekolah-sekolah pertanian : Cultuurschool, A.M.S dan H.B.S. Disusul kemudian 
gedung-gedung bank pemerintah seperti de Javasche Bangk (1916), N.I.Escompto (1929), N.I.Handels Bank (1938), dan Bank Nasional Indonesia (1938).

Sejalan dengan berdirinya gedung pemerintahan dan perkantoran, parit-parit pembuang air diatur sebaik-baiknya, waterloiding dibangun (1915), jaringan listrik diusahakan serta dikembangkan (1912), taman-taman kota dibangun, fasilitas olah raga dibangun serta sarana tempat tinggal dipercantik dan sarana ibadah bagi orang-orang Belanda diupayakan dengan baik, sehingga Kotapraja Malang dikenal dengan sebutan "de bloemenstad" dan dikumandangkan sebagai "kota pensiun" bagi orang-orang Belanda yang tidak kembali ke Negara Belanda. Seiring dengan berkembang pesatnya Kotapraja Malang tersebut, maka pada tahun1928 Kotapraja Malang menjadi ibukota Residensi Pasuruan (Team Sejarah IKIP - Malang, 1976:80 - 84).

Pada masa penjajahan Jepang, setelah Jepang menguasai seluruh Tanah Jawa, pada tanggal 7 Maret 1942, Panglima Tentara ke 16 mengeluarkan Undang Undang No.1 yang antara lain berisi tentang ketentuan-ketentuan Tata Pemerintahan. Tata Pemerintahan yang dimaksud yaitu balatentara Nippon melangsungkan pemerintahan militer untuk sementara waktu di daerah-daerah yang ditempatinya agar supaya mendatangkan keamanan dengan segera. Berdasarkan pengumuman Bulan Mei 1942, Kotapraja Malang yang telah jatuh ke tangan pemerintahan militer Jepang berubah menjadi Pemerintahan Malang-syū dan terbagi menjadi 4 ken (wilayah kabupaten) yaitu $\mathrm{Ma}$ lang-ken, Pasuruan-ken, Probolinggo-ken dan Lumajang-ken (Team Sejarah IKIP-Malang 1976:86-87).

Pada masa penjajahan Jepang, banyak perubahan-perubahan yang memaksa dan menguntungkan pemerintahan penjajahan Jepang. Organisasi-organisasi yang tumbuh dan berkembang di wilayah Malang- syū maupun Malang-ken antara lain yaitu Organisasi Rakyat seperti P.D.I (Perikatan Poetera Indonesia), serta K.B.I (Kepanduan Bangsa Indonesia), Organisasi Poetera (Pusat Tenaga Rakyat), Jawa Hokokai (Himpunan Kebaktian Rakyat), Organisasi Islam, Badan-Badan Militer, dan Tentara Sukarela Pembela Tanah Air (Boe-ei Giyugun).

Organisasi Poetera Cabang Malang diresmikan pada tanggal 16 Agustus 1943 dan diketuai oleh R.P.Soeroso. Poetera Malang bergerak di bidang penerangan kesehatan, pendidikan dan perekomian. Pembentukan organisasi ini kurang mendapatkan sambutan masyarakat di wilayah Malang-syu, Malangsyi maupuan Malang-ken, sehingga pada tanggal 29 Februari Poetera Malang-syu dibubakan. Organisasi Jawa Hūkūkai Malang-syū dilantik pada tanggal 9 Maret 1944 dan diketuai Minoru Tanaka dan R.P.Soeroso sebagai wakil ketua. Pada bulan September 1942, Organisai Islam di Malang didirikan yaitu organisasi Komite Umat Islam yang aktifitasnya terbatas pada peringatan hari-hari besar keagamaan. Setahun kemudian yakni sekitar bulan September 1943, organisasi Islam yakni Nadhatul Ulama dan Mohammadiyah diijinkan berdiri. Pada akhir November 1944, Jepang di Malang mendirikan Majelis Syuro Muslimin Indonesia (Masyumi). Organisasi Badan-Badan Militer di Malang membentuk badan militer Keibondan dan diresmikan pada Tgl. 15 Maret 1943 dengan tugas pokok pencegahan kebakaran, pertolongan kecelakaan, pemakaian alat komunikasi serta pengairan. Setelah persipan dianggap matang, pada Tgl. 3 Juni 1943, dilakukan peresmian Seinendan di seluruh wilayah $\mathrm{Ma}$ lang-Sȳu. Tugas pokok para Seimendan adalah latihan fisik, praktek perang gerilya serta pencegahan bahaya udara. Dalam usahan pembentukan Tentara Pembela Tanah Air, maka pada tanggal 11 Oktober 1943 dibuka pendaftaran bagi para calon.dan di wilayah Malang Sy $\bar{u}$ dibuka pada Tgl. 16 Februari 1944 dan hasil- 
nya pada Tgl.10 Agustus 1944 di wilayah Malang-Sȳ̄ dibentuk 5 daidan (Team Sejarah IKIP - Malang 1976:97-98).

Masa akhir pendudukan Jepang atas wilayah Malang ditandai dengan menyerahnya tampa syarat Pemerintahan Jepang kepada Sekutu, setelah pada Tgl. 6 Agustus 1945 Hoirosyima dan pada tanggal 9 Agustus Kota Nagasaki di bom atom oleh Amerika. Dengan demikian terjadilah kekosongan kekuasaan dan hal ini dimanfaatkan oleh rakyat Indonesia untuk merealisasikan kemerdekaannya, termasuk juga di wilayah Malang, maka tepat pada tanggal 17 Agustus 1945, dibawah Soekarno-Hatta mengumandangkan Proklamasi Kemerdekaan Indonesia (Team Sejarah IKIP - Malang 1976: 106-107).

\section{POTENSI NILAI KESEJARAHAN "CAGAR BUDAYA : BANGUNAN IN- DIS” DI KOTAPRAJA MALANG}

Sejalan dengan uraian Lintasan Sejarah Kota Malang tersebut, maka terdapat beberapa Bangunan "Cagar Budaya": yakni Bangunan Indis di Kota Malang yang mengandung nilai sejarah, seni dan bangunan-bangunan yang menandai jamannya. Berikut ini akan diuraikan potensi nilai kesejarahan Bangunan "Cagar Budaya": Bangunan-bangunan Indis" secara terpilih (Satrio,J.A,. 2012 : 15-20, Marzuki, L.H.., 2012: 240-250).

\section{Bangunan Indis: Bandara Abdul Rahman Saleh}

Sekitar 1937-1940, Pemerintah Belanda membangun beberapa pangkalan udara, antara lain Pangkalan Udara Maospati Madiun, Pangkalan Udara Panasan Solo, Pangkalan Udara Maguwo Yogyakarta dan Pangkalan Udara Malang. Pangkalan Udara Malang memiliki panjang landasan 1980 x 50 M, 526 DPL. Dengan demikian, Pangkalan Udara-Malang dapat didarati pesawat berbadan besar seperti Boomber, Glynmartin, Fokker dan Junkers. Pada masa Pendudukan Jepang, Pangkalan
Udara Malang digunakan sebagai tempat penimbunan perbekalan militer, sehingga Pemerintah Jepang memperpanjang landasan pacu pesawat. Pada Tgl.17 Agustus 1952, Pangkalan Udara- Bugisan, Malang berganti nama menjadi Pangkalan Udara Abdul Rahman Saleh untuk menghormati sosok Abdul Rahman Saleh sebagai Komando Operasional TNI AU II dan juga sebagai pelopor, perintis serta pejuang di bidang penerbangan. Bangunan bandara ini berada di Jl.Wisnuwardahan 133 Singosari, Malang dan saat ini di samping sebagai Pangkalan Udara Militer, juga digunakan sebagai penerbangan sipil komersial (Cahyono 2007:20-21).

\section{Bangunan Indis: Lembaga Pemasyara- katan Lowok Waru}

Bangunan ini telah mengalami pergantian 3 masa pemerintahan yaitu masa Pemerintahah Belanda, Pemerintahah Jepang dan masa Pemerintahan Kemerdekan Indonesia. Dibangun oleh Pemerintahan Belanda pada 1921, bersamaan dengan pada saat Pemerintahan Belanda membangun perumahan di kawasan Celaket. Pada masa pendudukan Jepang, gedung penjara ini gunakan sebagai tempat penampungan para pejuang untuk diiterogasi sekaligus disiksa. Pada saat Belanda memasuki kembali Kota Malang, bangunan ini dibumihanguskan oleh para pejuang kemerdekaan Indonesia di Malang hingga tinggal tembok penyekat saja. Hingga saat sekarang, bangunan ini masih difungsikan sebagai gedung lembaga pemasyarakatan dikenal dengan Lembaga Pemasyarakatan Lowok Waru (Cahyono 2007: 33).

\section{Bangunan Indis: Kliniek Lavalette}

Kliniek Lavalette yang sekarang dikenal dengan Rumah Sakit "Lavalette" tertelak di Jl. W.R.Supratman 10 dan nama Lavalette merupakan kependekan dari G.Ghr.Renandel de Lavalette, nama seorang pemilik klinik ini. Oleh karena perhatiaannya pada kesehatan masyarakat pada waktu itu begitu besar, beliau bersama 
Yayasan Stichting voor Malangsche Verteging, pada 1918 mendirikan klinik kesehatan yang sekarang berkembang menjadi rumah sakit di bawah pengelolaan P.T.Perkebunan Nusantara XI (Persero) (Leempt 1939:CXII, Cahyono 2007:33).

\section{Bangunan Indis: Kompleks Perumahan Pertama di Kotapraja Malang}

Komplek perumahan ini saat sekarang berada di Jl.Diponegoro, Celaket. Berdirinya kompleks perumahan ini, diawali pada Tgl. 13 April 1916 dalam rapat Dewan Kota : Gemeenteraad yang beranggotakan 8 orang Eropa, 2 orang pribumi dan 1 orang golongan Timur Asing, memutuskan untuk membangun perumahan untuk golongan orang Eropa yang dinekal dengan pengembangan kota I (Bouwplan I). Tujuan pembangunan perumahan ini antara lain untuk memecah keramain kota yang cenderung ke arah utara jalan menuju Surabaya. Pelaksanaan pembangunan perumahan, dimulai tgl.18 Mei 1917 dan daerah perumahan ini diberi nama Oranjebuurt, yaitu daerah orange nama keluarga kerajaan Belanda (Cahyono 2007:38).

\section{Bangunan Indis : Gedung Sekolah “ Neu- trale Schoolvereeninging".}

Bangunan ini sekarang menjadi Bangunan Sekolah Kolese Santo Yusup Malang, terletak di Jl.Dr.Soetomo 35. Gedung ini dibangun pertama kali tahun1922 digunakan untuk Neutraie Schoolvereeniging: Eropese Lagere School sampai tahun1947. Pada masa pendukukan kembali Belanda yakni masa Clash, gedung ini dibumi-hanguskan dan pada tahun1951 gedung ini dibeli oleh Misi Katolik Malang menjadi gedung Sekolah Menengah Katolik Tionghowa Indonesia: Ho-Ind Chung Hsueh (Leempt 1939: CXXIX, Cahyono 2007:39).

\section{Bangunan Indis: Gedung Sekolah R.K.Zusterschool, Tjelaket}

Bangunan ini terkenal dengan nama R.K.Zusterschool, Tjelaket dan dibangun atas usulan Mgr.Staat (Uskup Katolik Indonesia) pada tgl 8 Maret 1900 dan mulai dibangun pada tgl 3 Maret 1900 oleh arsitek Westmaas dari Surabaya. Kawasan ini sebelumnya milik Tuan Stenekers dan kemudian dibeli oleh pihak gereja untuk dibangun gedung dan mulai digunakan pada tahun1930 sebagai sekolah pendidikan guru dengan nama SPG Santo Agustinus. Pada masa pendudukan Jepang, sekolah ini dihentikan untuk sementara dan gedung tersebut difungsikan sebagai Sekolah Militer Divisi VII Suropati. Pada masa Clash I th 1947, gedung ini dibumi-hanguskan oleh pejuang kemerdekaan Indonesia, guna menghindari Belanda masuk ke Malang. Pada tanggal 8 April 1951 dimulai pembangunan kembali dan tgl.15 Juli 1951 gedung tersebut berubah nama menjadi gedung SMA Co-Jesu dan diresmikan oleh Monseigneur tgl.13 Januari 1955 (Leempt 1939: CXXVIII -CXXIX, Cahyono 2007:40).

Bangunan Indis: Gedung Sekolah R.K.Fraterschool, Tjelaket

Bangunan ini saat sekarang dikenal dengan Gedung Sekolah Frateran, terletak di Jl.Jaksa Agung Soeprapta 21. Gedung ini dibangun pada tahun1926 dengan arsitek : Biro Arsitek Hulswit, Fermont dan Ed Cuypers dari Batavia. Gedung ini dibangun untuk sekolah umum dan untuk para frater : pastor muda dari Kongregasi Frater Bunda Hati Kudus Propinsi Indonesia yang didirikan oleh Mgr.Andreas Ignatius Schaeprman. Gedung diresmikan pada tgl.13 Agustus 1973 di Utrecht, Belanda. Pada masa Clash I yakni tahun 1947 gedung ini juga mengalami bumi-hangus untuk mencegah Belanda kembali ke Malang (Leempt 1939: CXXVIII, Cahyono 2007:41).

\section{Bangunan Indis: Loge Kolojian - RSUD Saiful Anwar}

Bangunan ini dianggap bangunan paling bersejarah, karena merupakan lokasi atau situs pertama kali Belanda memasuki Malang pada tahun1767. Kemudian di tempat ini Belanda membangun benteng pertahanan yang dikenal dengan Loge/Loji yang kemudian dikenal 
dengan sebutan Kelojian - Kelodjen. Benteng tersebut dibangun tepat di pinggir Kali Brantas dan apabila sewaktu-waktu terjadi penyerangan oleh bangsa pribumi dapat melarikan diri dengan mudah melalui saluran Kali Barntas. Pada tahun1800-an saat bangsa Belanda bermukim di sekitar alun-alun, benteng Loge dijadikan Militair Hospitaal : Rumah Sakit Tentara Belanda menyatu dengan kompleks militer Belanda hingga area kawasan Lapangan Rampal. Pada masa pendudukan Jepang, oleh Jenderal Ter Poorten diserahkan pada Pemerintahah Jepang sampai tahun1945. Setelah Agresi Militer I tahun1947 setelah bertukar dengan Rumah Sakit Sukun, lokasi ini dijadikan rumah sakit umum oleh Pemerintah Propinsi Jawa Timur dan pada tgl 12 Nopember 1979 berganti nama Rumah Sakit Dr.Saiful Anwar (Cahyono 2007:42).

\section{Bangunan Indis: Komplek Pertokoan Wingkel Complex Lux.}

Saat sekarang gedung kompleks pertokoan ini dikenal dengan Kompleks Pertokoan Avia. Kompleks pertokoan Wingkel Complex Lux dibangun pada tahun1930-an bersamaan dengan pesatnya perkembangan pertokoan di daerah Kayutangan. Toko Semarang, Automobielhandel P.Bouman dan Chevrolet dealer yang berada di kompleks pertokoan ini, membuat kompleks pertokoan ini banyak dikunjungi kaum Eropa dari luar Malang. Di depan kompleks pertokoan terdapat Jam Penunjuk: arah penunjuk jalan di dalam kota serta landmark kota Malang (Leempt 1939:CXLIV, Cahyono 2007:44).

\section{Bangunan Indis: Kantoor Electriciteit mij Aniem N.V.Malang}

Kantoor Electriciteit mij Aniem N.V.Malang atau Kantor Perusahaan Listrik Negara Cabang Malang dibangun pada tahun 1930-an dengan ciri khas Nieuwe Bouwen yang beratap daatr, gevel horizontal dan volume bangunan berbentuk kubus. Bangunan ini memiliki ruang-ruang bangunan tertutup yang menyatu dengan tebing Kali Brantas. Kemungkinan tuang-ruang tertutup tersebut untuk menyelamatkan alat-alat vital listrik serta tempat berlindung di saat terjadi perang pada masa Perang Dunia II (Cahyono 2007:46).

\section{Perempaan Kayu Tangan : Kajoetangan Smeroestraat - YMCA Hotel}

Pertokoan di Perempatan Kayutangan saat sekarang Jl.Basuki Rahmat - Jl.KahuripanJl.Semeru - dibangun oleh arsitek Karel Bos dengan penanda ciri bangunan kembar sebelah kanan - kiri perempatan, pada tahun1936 dan kedua bangunan kembar tersebut merupakan penanda pintu gerbang masuk ke arah Jl.Semeru. Dibangun dengan gaya arsitektur Nieuwe Bouwen dan kedua bangunan kembar mempunyai menara untuk pengamatan lingkungan sekitar. Tepat di sisi timur perempatan Kayutangan dibangun Hotel MABES (sisi utara) dan Malangsche Apotheek (sisi selatan). Hotel MABES berganti nama menjadi YMCA Hotel dan saat sekarang gedung hotel tersebut kantor Bank BCA (Leempt 1939; CXLIV, Cahyono 2007:54).

\section{Bangunan Indis: Telepoonk Kantoor}

Teleponk Kantoor dahulu merupakan Kantor Pos, telegram dan telepon dibanguin tgl.8 Juli 1909 oleh Ir.S.Snuyf dan BOW. Sambungan telepon saat itu masih dikelola swasta dan pada tahun1917 diserahkan ke pihak Kotapraja Malang dengan jumlah sambungan telpon 1000 sambungan; sebelumnya 275 yang kebanyakan pemakainya adalah orang-orang Eropa. Pada masa Clash I, th 1947 gedung tersebut ikut dibumi-hanguskan dan menjelang kedatangan Belanda II, gedung tersebut menjadi anjungan kehormatan pucuk pimpinan Belanda dalam menyambut Belanda masuk kembali ke Kota Malang (Leempt 1939:XVI, Cahyono 2007:64)

\section{Bangunan Indis: Toko Oen}

Toko Oen dahulu bernama Oen Ice Cream Palace Patissier mulai dibuka pada tahun1930 dan merupakan restoran satu-satunya 
dari keluarga China. Restoran ini menyediakan menu khas Belanda dan dibangun didepan gedung Concordia, tempat berkumpulnya semua warga Belanda di Malang. Restoran ini sampai sekarang dipakai tempat nostalgia warga Belanda yang wajib dikunjungi dan bangunannya masih asli tidak berubah. Pada berlangsungnya Kongres KNIP tgl 25 Februari 1947, restoran ini menjadi tempat berkumpulnya peserta konggres untuk istirahat makan siang. Restoran ini pada saat Clash I selamat dari gerakan bumihangus sehingga arsitekturnya masih "asli" (Cahyono 2007:66)

\section{Bangunan Indis: Gereja Katolik Hati Ku- dus Yesus}

Semula bangunan gereja ini dibangun pada tahun1897 - 1905 dan kemudian pada tahun1905 dimulaikan dibangun gereja bergaya Gothik yang saat sekarang dikenal dengan Gereja Kayutangan atau Gereja Katolik Hati Kudus Yesus. Dibangun oleh arsitek M.J.Hulswit yakni arsitek Belanda ahli restorasi gereja-gereja bergaya Gothik. Di dalam pintu masuk gereja terdapat prasasti dalam bahasa Belanda yang artinya: gereja ini dipersembahakan kepada Hati Kudus Yesus, didirikan berkat kemurahan hati yang mulia Monseigneur ES Luypen, dirancang oleh M.J.Hulswit dan semasa "penggembalaan" yang terhormat romoromo GDA, Joncbloed dan FB Meurs. Pelaksanaan pembangunan gedung, tahun 1905, dikerjakan oleh pemborong YM.Moseoigneut Edmundus Sijbrandus Luypen, Uskup Tituler dari Eropa, Vikaris Apostolik dari Batavia. Menara gereja ciri kas bangunan Gothik pada tahun 1910 belum ada, baru pada tgl 17 Desember 1930 kedua menara gereja gaya khas Gothic selesai dibangun (G.Vriens S.J 1972: 75-77, Leempt 1939 :LXXXI, Cahyono 2007:67).

\section{Bangunan Indis: Societiet Concordia - "Pertokoan Sarinah" - Kongges KNIP}

Bangunan Societiet Concordia yang saat ini menjadi Kompleks Pertokoan Sarinah Malang, semula merupakan pendopo Kabupaten Malang, sesuai Surat Resolusi 31 Oktober 1820 no.16, Bupati Surabaya. Berdasarkan isi surat tersebut, pendopo tersebut merupakan rumah dinas Raden Panji Wielasmorokoesoemo setelah diangkap menjadi Bupati Malang dan Ngantang yang berganti nama menjadi Raden Tumenggung Notodiningrat. Dengan demikian semua gedung tersebut merupakan pendopo; Kantor Bupati Malang sebelum berada di lokasi sekarang. Hingga sampai tahun1989 lokasi ini menjadi kantor bupati dan setelah itu tempat tersebut diambil alih Belanda kemudian dijadikan gedung Societiet Concordia, dibangun sebelum tahun 1900 dengan gaya Indische Empire dengan ciri utama kolom-kolom gaya Yunani Kuno. Setelah tahun 1914, dimana Malang menjadi Kotapraja Malang, gedung bergaya Indische Empire tersebut dirobohkan dan digantikan dengan model bangunan kolonial modern untuk mengakomodasi kebutuhan tempat rekreasi orang-orang Belanda seperti halnya meja tempat main kartu, meja bilyard, perpustakaan serta gedung pertemuan.

Pada 25 Pebruari sampai dengan 5 Maret 1947, gedung tersebut digunakan sebagai tempat perhelatan penting yaitu Kongres KNI Pusat yakni rapat besar cikal bakal DPR-RI tingkat nasional. Kongres membahas masalah-masalah penting yang menjadi agenda perjuangan Bangsa Indonesia saat itu dengan dihadiri tokoh-tokoh seperti Ir.Soekarno, Moh.Hatta, Edward FE Douwes Dekker, Ki Hajar Dewantara, Dr.Soetomo, Panglima Soedirman, Bung Tomo dan para pembesar wakil negaranegara di dunia. Jumlah tamu yang hadir pada waktu itu berjumlah sekitar 1.500 orang, sehingga hotel-hotel di Malang dan Batu penuh sesak. Inilah peristiwa bersejarah yang terjadi di gedung Societiet Concordia pada tahun1947. Pada tahun1948, menjelang Clash I gedung ini dibumi-hanguskan oleh para pejuang kemerdekaan Indonesia untuk mencegah Belanda menduduki kembali kota Malang. Gedung ini kemudian diratakan dengan tanah, kemudian dibangun pertokoan yang sekarang bernama 
Sarinah (Leempt 1939 :CXLV, Cahyono 2007: 68-69).

\section{Bangunan Indis: Javasche Bank dan Ned.Ind.Escompto Bank/Mill.}

Bangunan Javasche Bank dibangun pada tahun1915 oleh biro arsitek Hulswit, Fermont \& Ed.Cuypers dari Batavia, terletak di alon-alon kota Malang. Pada masa pendudukan Jepang, Javasche Bank merupakan satu-satunya yang diijinkan Jepang menghimpun dana dari seluruh bank, dengan tujuan untuk mengawasi secara ketat seluruh perekonomian dengan satu pintu. Pada tahun1947 gedung ini dibumi-hanguskan oleh pejuang kemerdekaan Indonesia untuk membendung agar Belanda tidak masuk ke Malang dan kemudian dibangun kembali sesuai arsitektur aslinya dan saat sekarang dipakai sebagai gedung Bank Indonesia Cabang Malang.

Di samping bangunan Javasche Bank, juga dibangun Escompto Bank/Mil pada tahun1929 yang merupakan jaringan bank di seluruh kota besar Indonesia. Dibangun oleh biro arsitek Hulswit, Fermont \& Ed.Cuypers dari Batavia, terletak di alon-alon kota Malang. Saat sekarang bangunan tersebut digunakan sebagai Kantor Pajak.

\section{Bangunan Pendopo Kabupaten}

Berdasarkan Surat Resolusi 31 Oktober 1820 no.16, pendopo tempat tinggal Bupati Malang ini dibangun tahun 1839 oleh Raden Panji Wielasmorokoesoemo dan setelah diangkat menjadi Bupati Malang dan Ngantang berganti nama Raden Tumenggung Notodiningrat. Saat itu Kabupaten Malang merupakan bagian wilayah Karisidenan Pasuruan berdasarkan Staadblad 1819 no.16. Bangunan Pendopo Kabupaten Malang telah digunakan sebagai tempat tinggal bupati pertama sejak tahun1839 hingga bupati ke 18, tahun 2002 (Cahyono 2007: 89)

Bangunan Indis: Bestuurskantoor - Gedung Kantor Residen Malang

Oleh karena Kabupaten Malang berdasarkan Staadblad 1819 no.16 merupakan wilayah Karisidenan Pasuruan, maka di Kota Malang ditempatkan seorang pejabat asisten residen, pada tahun1824 memempati gedung kantor Asisten Residen sekarang Kantor Pos. Oleh karena pada tahun1928 Malang menjadi ibu kota residen, maka pada tahun1936 dibangunlah gedung Bestuurskantor yakni kantor Risiden Malang, di lingkungan alun-alun bersebarangan dengan Pendopo Kabupaten. Gedung tersebut dibangun oleh arsitek Ir.M.B.Tideman sampai sekarang tidak mengalami perubahan berarti. Saat sekarang gedung ini menjadi Kantor Perbendaharaan dan Kas Daerah dengan tidak mengalami perubahan berarti (Leempt 1939 :XVI, Cahyono 2007:99).

\section{Bangunan Masjid Jami Malang}

Masjid Jami ini dibangun tahun1875, dengan tanah lapang di depannya 7 tahun kemudian yakni tahun1882 dibangun Alunalun Malang. Masjid ini termasuk masjid beryoni di Jawa Timur dengan tiang utama sebanyak 20 buah dan 4 tiang besar. Di belakang masjid terdapat makam beberapa kerabat bupati Malang, salah satunya yang masih ditempat kemungkinan Kijaie Tumenggung Mertonegoro setelah menjadi Bupati Malang I. Kerabat makam lainnya telah dipindahkan ke makam Gribik (Leempt 1939 :XCVII, Cahyono 2007:102).

\section{Bangunan Indis : Protestansche Kerk - Ger-} eja GIB Immanuel, Aloon-Aloon.

Bersebelahan dengan bangunan Masjid Jami, yakni di perempatan Aloon-Aloon berdirilah bangunan Gereja Kristen Protestan yang dibangun pada 1861. Oleh karena bentuknya sangat sederhana kemudian dibongkar oleh Belanda dan dibangun kembali dengan gaya Gothic pada tahun1912 (Leempt 1939 : LXXXX, Cahyono 2007:104).

\section{Bangunan Indis : Pasar Petjinaän - Pasar Besar Malang.}

Pada rencana perluasan kota ke VI tahun 1914-1917 dibahas pentingnya pasar dalam perkembangan kota. Sejak berdiri Kotapraja 
Malang, belum mempunyai pasar kecuali pasar pecinaan di daerah Pecinaan. Maka mulailah digagas pembangunan pasar dan dimulai di daerah dekat Kayutangan di tepi Kali Brantas, namun tidak memadahi dan sulit berkembang. Maka mulailah dirancang pasar di sekitar Pecinaan dan disambut baik oleh para pedagang China dan Arap dan mulai dibangun 1920 - 1924 dikenal dengan Pasar Petjinaän dan berhasil dibangun 29 los bangunan pasar. Untuk menampung perkembangan pasar di luar Petjinaan maka pada 1932 dan 1934, dibangun pasar Klojen, Pasar Boenoel, Pasar Bareng, Pasar Oro' Dowo, Pasar Kebalen dan kawasan Waroengcentral Mergosono (Leempt 1939: 151 - 153, Cahyono 2007:108).

\section{Bangunan Indis : Kelenteng Eng An Kiong- Toa Pek Kong}

Bangunan tempat peribadatan pemeluk agama $\mathrm{Ji}$ Too dan Sik, berada di Jl.Kenteng sekarang Jl.Laksana Marta Dinata dan berdasarkan prasasti, diperkirakan bangunan tersebut dibangun pada 1825. Dan berdasarkan buku dari Khong Kouw Sian, bangunan tersebut dibanguan atas inisiatif Letnan Kwee Sam Hway (1842-1963) dan setelah meninggal diserahkan kepada anaknya Letnan Kwee Siang Ing serta Letnan Kwee Sioe Go. Pada 1890 dilakukan perluasan bangunan oleh kontraktor Tionghoa setelah menyelesaikan proyek pembuatan jalan kereta api Malang-Blitar.

Pemilihan lokasi kelenteng di daerah pertukangan ini diperkirakan terkait dengan toponimi daerah-daerah bekas pelarian penduduk setempat, saat penyerangan Sultan Demak. Saat itu, kaum Tionghoa bersatu padu dengan penduduk setempat mengungsi dan menetap sementara di daerah Tumpang dan mulai menenam pohon Buah Mata Naga (kelengkeng) dan padi unggul; beras JawaTumpang. Setelah dirasa aman, semua pengungsi mulai memasuki daerah Malang, penduduk beternak di daerah Kedung-Kandang, kaum Tionghoa mulai membedah kota dari Kuto Bedah. Kelenteng yang dipercaya sebagai tolak-balak didirikan tepat akan memasuki dataran Malang, selanjutnya mulai berdagang dan berkembanglah daerah Pecinaan, membuka daerah permebelan - daerah Pertukangan, mengolah tanah menjadi sawah - daerah Sawahan, daerah ereng-ereng daerah Bareang serta oro-oro yang sangat luas - daerah Oro-oro Dowo (Leempt 1939 :XCVI -XCVII, Cahyono 2007:173).

\section{Idjen Boulevard - Bangunan Indis R.K.Ka- thedraal - Villapark}

Pada saat Jl.Kayutangan yakni jalan utama lintas Surabaya - Blitar, telah penuh dengan bangunan komersial, tahun1924 Pemerintah Kotapraja Belanda, merencanakan untuk memecah keramaian pada Program Bouwplan VI, dengan membangun jalan arah timur-barat, dimulai dari Statiun Baru Kereta Api. Daendels Boulevard (Jl.Kertanagara sekarang) memotong Kayutangan, Jalam Semeru dan berakhir di Smeroe Park: Taman Ijen - Idjen Boulevard yang sebagian tanahnya sudah dikuasi oleh N.V. Bouwmaatschappij dengan titik orientasi adalah Gunung Kawi. Panjang jalan Idjen Boulevard hampir $1 \mathrm{~km}$ dan dipenuhi dengan tananan bunga nan indah dan di kanan kirinya terdapat bangunan kawasan Villapark yakni perumahan elite yakni tempat tinggal para pejabat pemerintahan :gemeente dan para kaum elite Belanda. Di sebelah barat jalan terdapat 48 buah rumah dan di sebelah timur 47 buah rumah yang sebagian besar saat ini arsitekturnya masih dipertahankan. Kawasan Idjen Boulevard sampai saat ini dijadikan salah satu ikon Kota Malang yang wajib dikunjungi, sehingga lanskap kawasan Idjen Boulevard, dijadikan kawasan cagar budaya dengan didukung Peraturan Pemerintah Daerah Kota Malang (Leempt 1939:XCIV-CCV, Cahyono 2007:136).

Di lingkungan Idjen Boulevard, tepatnya di sisi timur Boering Plein, pada 1929 Mgr.Clemens van der Pas O.Carm, berkeinginan membangun gereja katedral untuk wilayah 
Apostolik Keuskupan Malang. Peletakan batu pertama dilakukan 11 Februari 1934, 28 Oktober 1934 diresmikan dan dipersembahkan kepada Santa Theresia serta masuk paroki Katedral St.Theresia. Untuk mengantisipasi perkembangan penduduk serta pendidikan, maka di lingkungan paroki tersebut pada tahun1926 didirikan Sekolah Dasar berbahasa Belanda di Jl.Semeru. Tahun 1930 didirikan Sekolah Dasar "Ongko Loro: Inlandsche School ze Klasse di Betek 1936 didirikan Taman Kanak-Kanak: Frobelschool dan SD St.Ursula di J1.Paderman dan tahun1936 didirikan SMU: AMS.Algemene Middleboar School, St.Albertus di Jl.Talang. Pada saat Clash I berlangsung di Malang tahun1947, para pelajar SMU St.Albertus bergabung menjadi Tentara Pelajar (TRIP) yang kemudian menjadi perlawanan Belanda di Jl.Salak dan saat sekarang dibangun monomen kepahlawan TRIP, tepat di depan atau sisi barat R.K.Kathedraal yang saat ini disebut Gereja Katedral Katolik, Keuskupan Malang : Gereja Santa Maria Bunda Karmel (Leempt 1939:XCIV-CCV, Cahyono 2007:134-143).

\section{J.P.Coemplein met Gemeentehuis - Stasiun}

\section{Kota Baru - Tugu Alun-Alun Bunder}

Telah dijelaskan di muka, bahwa sebelum 1914, Malang masih merupakan bagian wilayah administratif Karisidenan Pasuruan dan kekuasaan tertinggi di Malang adalah Assisten Risiden yang berkantor di selatan AloonAloon. Setelah Kota Malang dinaikkan menjadi Kotapraja Malang : Gemeente Malang, tanggal 1 April 1914, Kota Malang berhak memerintah daerahnya sendiri dengan dipimpin oleh seorang pejabat Burgermeester: Walikota. Jabatan walikota saat itu dirangkap oleh Assisten Residentie sampai akhir 1918 dan baru 1919 Malang memiliki walikota pertama yaitu Burgermeester HI Bussemaker. Aloon-Aloon lama sebagai simbol pemerintahan sebelum kotapraja, dianggap sudah tidak mewakili lagi gaya pemerintahan baru yang lebih modern, sehingga diusulkan untuk membuat pusat pemerintahan baru yaitu di daerah J.P. Coemplein yakni bernentuk aloon-aloon bundar. Pada 1920 dibuatlah perencanaan kota yang di dalamnya termasuk pembuatan Gedung Gemeenhuis yakni Balai Kota. Pada tgl 14 Februari 1927 diputuskan oleh Dewan Kotapraja Malang segera dimulai pembangunannya dengan anggaran biaya F.287.000. Pembangunan Balai Kota dilaksanakan 1927 sampai 1929 dan mulai ditempati bulan September 1929 oleh walikota kedua yakni Ir.E.A.Voorneman. Pada saat terjadi Angresi Belanda I : Clash I, tahun 1947, gedung Balai Kota ikut dibumi-hanguskan, namun kemudian dibangun kembali sesuai dengan desain arsitektur aslinya hingga sampai sekarang (Leempt 1939, Cahyono 2007: 118120).

Tepat di sisi timur Balai Kota terdapat bangunan dikenal dengan Satiun Kota Baru hasil pembangunan tambahan tahun 1930. Sejak saat baru pertama kalinya jalur kereta api Surabaya-Malang dibuka tahun 1876, di sepanjang Jalan Raya Kayutangan sudah ada beberapa rumah orang Eropa dan selebihnya masih berupa sawah dan sebelah timur jalan raya tersebut telah berdiri kompleks tangsi militer sekarang dikenal dengan Kompleks Rampal. Dengan alasan keamanan, maka statiun kereta api ditempatkan di sebelah timur rel kereta api, berhadapan dengan Kompleks Tangsi Militer Rampal.

Sesuai dengan perencanaan dan pengembangan pembangunan Kotapraja Malang, sejalan dengan pemikiran arsitek kota Ir.Herman Thomas Karsten untuk lebih memperindah lanskap Kota Malang, maka pada 1930, Statiun Kereta Api Kota Baru dipindak menghadap barat dan arah kedatangan statiun berorientasi ke puncak Gunung Api Kawi yang eksotik. Untuk menandai kesan monomental dibangunlah jalan kembar dengan taman di tengahnya menuju Aloo-Aloon Bunder. Desain bangunan Satiun Kota Baru pada waktu itu dilengkapi dengan bangunan terowongan bawah tanah yang menguhungkan antara peron 
2 ke peron 3 dengan tujuan untuk perlindungan, apabila sewaktu-waktu terjadi peristiwa serangan udara (Cahyono 2007:128-129).

Tepat di tengah-tengah Aloon-Aloon Bunder pada tgl.17 Agustus 1946, dilakukan peletakan batu pertama untuk menandai pembangunan Monomen Tugu Nasional untuk memperingati Proklamasi Kemerdekaan Indonesia. Pada saat pembangunan tugu mencapai $95 \%$, terjadi peristiwa Clash I yang memaksa pembangunan dihentikan dan tugu yang sedang dibangun tersebut pada tgl 23 Desember 1948 dirobohkan dan dihancurkan hingga tinggal pondasinya saja. Setelah kondisi politik stabil dan Indonesia kembali ke pangkuan ibu pertiwi, maka pembangunan tugu tersebut di mulai lagi dan pada tgl 20 Mei 1953, Tugu Nasional tersebut diresmikan oleh Presiden Soekarno (Cahyono 2007:114-117).

\section{Bangunan-Bangunan Indis Lainnya}

Masih banyak bangunan Indiis lainnya yang mengandung nilai-nilai arsitektur serta menjadi saksi sejarah perkembangan Kotapraja Malang sejak kekuasaan Belanda hingga pendudukan Jepang, di antaranya yaitu jaringan jalan dan jembatan, jaringan tren serta statiunstasiunya, jaringan lori pengangkut tebu, rumah-rumah ibadah, langgar, gereja Jawa, rumah sakit, jaringan waterleiding, kampongkampoeng kota, kompleks Pecinan, jaringan terminal bus-grobak-becak tempoe doeloe dan kantor-kantor pemerintah. Bangunann itu menandai bahwa Kotapraja Malang dari tahun ke tahun mengalami perkembangan pesat sebagai kota pusat pemerintahan, pusat perkantoran perkebunan tebu - kopi dan sebagai kota pemukiman yang eksotik bagi Bangsa Eropa (Leempt, 1939).

Bangunan-bangunan yang diuraikan tersebut di atas, merupakan penanda jaman proses berkembanganya Kotapraja Malang dari masa penjajahan Belanda, Jepang hingga penanda Sejarah Kemerdekaan Indonesia. Di sisi lain dipandang dari sisi seni artsitektur, bangunan- bangunan tersebut merupakan penanda alkuturasi budaya Eropa, China dan pribumi yang teraktualisasi secara nyata dalam arsitektur bangunan-bangunan Indis. Di balik kemegahan arsitektur bangunan- bangunan Indis tersebut tersimpan perirtiwa penting kesejarahan masa lalu, sehingga layak dikategorikan sebagai bangunan "Cagar Budaya".

Sebagai bangunan "Cagar Budaya" yang mengandung nilai sejarah, penanda jaman perkembangan Kotapraja Malang dan nilai arsitektur Indis, maka hal ini merupakan sumber potensi untuk dimanfaatkan sebesar-besarnya untuk proses pembelajaran kesadaran sejarah, pengenalan jati diri Kota Malang dan pada akhirnya dapat dikembangkan serta dikemas untuk kesejahteraan masayarakat di Kota Malang. Tergerak oleh rasa kecintaan akan nilainilai sejarah beberapa bangunan Indis yang mencermikan perjalanan panjang Kotapraja Malang dan ditunjang keinginan untuk mengemas bangunan "Cagar Budaya" Indiis (Soekiman 2000: 21-39) tersebut untuk kesejahteran masayarakat, maka Yayasan Inggil bekerjasama dengan Pemerintah Kota Malang yakni Dinas Pariwisata dan Kebudayaan Kota Malang pada tahun2006 menggagas serta menyelenggarakan perhelatan akbar Even Malang Kembali berbasis pada nilai kesejarahan dan seni tradisi bangunan Indis Kotapraja Malang.

\section{MODEL PEMANFAATAN"CAGAR BU- DAYA : BANGUNAN INDIS” UNTUK KEGIATAN "EVEN MALANG KEM- BALI"}

Berpijak pada Lintasan Sejarah Kotapraja Malang dan berdasarkan Staadsblad no.297 Tgl. 1 April taoen 1914, maka pada setiap tgl 1 April tahun berjalan, diperingati sebagai Hari Jadi Kotapraja Malang, hingga sampai sekarang. Dalam kaitannya dengan hal ini, untuk mengungkap kembali Jati Diri Malang sekaligus melakukan pembelajaran sejarah kepada masyarakat, maka digagaslah oleh 
Yayasan Inggil (Inggil Documentary - Rumah Makan Inggil) yang dipelopori oleh Cahoyo untuk menyelenggarakan "Even Malang Kembali". Tujuan utama adalah untuk mengungkap kembali jati diri Malang dan sekaligus melakukan pembelajaran sejarah kepada masyarakat dengan menampilkan fakta-fakta dokomen, foto, perangkat, makanan khas masa kolonial, adad-itiadat dan kesenian abad XIX serta XX dalam kaitannya bangunan-bangunan Indis yang berkaitan langsung dengan lintasan sejarah lahirnya Kotapraja Malang. Even Malang Kembali pertama kali diselenggarakan pada tgl 22 Mei - 25 Mei 2006 di Taman Ijen atau Idjen Bouleward. Setelah tahun itu dilakukan setiap bulan Mei tahun berjalan, berturut-turut 2007, 2008, 2009, 2010, 2011, dan 2012.

Even Malang Kembali 2006 mengangkat tema serta mengungkap berdirinya Kotapraja Malang tahun 1914 sampai dengan pendudukan Jepang atas Kotapraja Malang tahun 1942. Even Malang Kembali 2007 mengangkat tema tentang pengaruh serta kegiatan Jepang mulai 1942 sampai Clash 1947. Pada Even Malang Kembali tahun2006 telah banyak menggunakan media "Cagar Budaya":Bangunan Indis untuk mengungkap perjalanan sejarah berdirinya Kotapraja Malang sejak pertama kali Belanda menginjakkan kakinya di daerah Malang tahun 1767 hingga tahun 1914 serta masa pendudukan Jepang atas Malang hingga tahun 1942. Jejak-jejak penanda sejarah yang ditampilkan antara lain foto dokumentasi Gedung Benteng Belanda Loge tahun.1767, foto domumentasi gedunggendung pemerintahan tahun 1917 - 1942, foto dukumentasi Malang Bumi-Hangus, dan beberapa aneka makanan serta jajanan tradisional ala Malang Tempoe Doeleo (Cahyono 2007).

Adapun model pengemasan bangunan " Cagar Budaya” Indis untuk kegiatan Evan Malang Kembali adalah sebagai berikut :

1. Perhelatan akbar Malang Kembali dilaksanaaan berkaitan dengan peringatan Hari Jadi Kotapraja Malang 1 April 1914 dan diselenggarakan setiap bulan Mei tahun berjalan, berlokasi di Bolulevat Jl.Besar Ijen di pusat Kota Malang. Dilaksanakan pada bulan Mei dan berdekatan dengan hari jadi Kotapraja Malang adalah untuk mengenal ulang lintasan sejarah Kotapraja Malang sejak berdirinya serta perkembangannya hingga masa sekarang. Perhelatan akbar itu juga disesuaikan dengan momentun citra Pariwisata Budaya khususnya citra pariwisata budaya Kotapraja Malang.

2. Agar perhelatan akbar Malang Kembali betul-betul mencermikan perhelatan masyarakat Malang maka Yayasan Inggil melibatkan seluruh komponen masyarakat seperti Dewan Kesenian, PHRI, HPI, KADIN, PAKANDAJU, Museum Se-Jawa Timur, para juru Kunci Situs Purbakala, Sanggar atau Organisasi Kesenian Tradisi, Asosiasi Pengrajin Kota Malang, IDI, IDGI, PMI, TRIP, Veteran, POLMA, PAMORI, Komunitas Sepeda Uncel, Komunitas Mobil Antik, Pagujuban Kuda Tunggang, Pagujuban Dokar Wisata, Media Cetak serta Elektronika, WULAN, USAR, UKM, Perguruan Tinggi Negeri dan Swasta, Komunitas Fotografi, Filateli, Film, Dewan Anak, Pagujuban Komedi Monyet, Perwosi, Pagujuban Kaligrafi, Pengrajin Batu Mulia, Asosiasi Pedagang Barang dan Batu Akik, Benda Pusaka, Pagujuban Pijat Tradisonal, Pagujuban Macapat, Para Pakar Sejarah dan Arkeologi dan beberapa pedagang asongan.

3. Agenda acara kegiatan Even Malang Kembali antara lain mencakup (a) Diorama Sejarah dan disesuaikan 
dengan tema kegiatan Even Malang Kembali, (b) Panggung Rakyat untuk mewadahi pentas panggung berbagai jenis kesenian rakyat seperti kesenian ludruk, wayang kulit, wayang beber, wayang topeng serta wayan topeng panjai, ketoprak, tajup, andong Malangan, mocopat, keroncong, gambus, oqshidah dan sholawatan,(c) Pasar Rakyat untuk mewadai berbagai kegiatan sajian seperti sajian makanan-jajanan tempoe doeloe, kerajinan lama - tempoe doeloe, pamer pusaka, ahli nujum, barang-barang koleksi tempoe doeloe, dan tata pamer berbagai arsip kuno, (d) Sajembara - untuk mewadai aneka kegiatan seperti kegiatan lomba fotografi, mewarnai, melukis, busana anak, mocopat, kakangmbakyu cilik, dolanan anak dan kegiatan tata pamer busana batik, (e) Workshop - untuk mewadai aneka kegiatan yang berkaitan dengan masalah industri tradisional serti industri keramik, gerabah, bengkel tari, ukir batik, wayang kulit, karawitan, kaligrafi, pencak silat, ludruk, tari topeng dan permasalahan kerajinan rakyat proses pembuatan keris, dan (f) Upacara adat - untuk mewadai aneka kegiatan yang berkaitan dengan upacara petik panen, upacara ruwatan, upacara musik lesong gejogan, upacara ritual Gunung Kawi serta kegiatan upacara pijetan.

4. Fokus pencapaian kegiatan Even Malang Kembali, dirumuskan sebagai berikut : (a) untuk mengenal jati diri - untuk kegiatan ini maka disediakan media yang menunjang yaitu berupa stand berukuran 100 x 4 meter untuk tata pamer data arsip asli, benda cagar budaya asli ditinjau dari segi arkeologis, foto serta dokumentasi benda-benda penunjang fakta sejarah yang ditata berdasarakan tata urutan kronologis, dan foto serta dokumentasi yang berkaitan dengan peristiwa penting dalam Lintasan Sejarah Malang, (b) penghematan tenaga, waktu dan biaya - untuk pencapaian ini maka disajikan data-data fakta sejarah berupa benda asli, dokumen asli dari luar Malang serta luar negeri ke area Even Malang Kembali-sehingga pengunjung dapat menghemat waktu serta biaya, cukup mengopserfasi di lokasi Even Malang Kembali dan tidak perlu mengopserfasi di tempat aslinya, (c) membantu perekomnomian rakyat - untuk mencapai hal ini maka dibuatlah stand-stand untuk menambah incame pendapan para pengrajin dan hal ini berdampak terhadap meningkatnya kebutuhan tradisi di pasar, sehingga ikut mendongkrak naiknya incame pendapatan para pengajin di dalam kota serta luar kota Malang, (d) menemukan solusi industri rakyat - untuk mencapai tujuan ini maka kegiatan Even Malang Kembali diarahkan untuk menjadi ajang inovasi solusi nyata perkembangan permasalahan rakyat. Prasyarat para peserta Even Malang Kembali diwajibakan menggunakan semua peralatan, perlengakapan, busana, serta jenis dagangan yang berbasis tradisi dan hal ini akan menumbuhkan budaya hemat, inovatif: menggunakan bahan bakar arang, batu bara, minyak jarak sebagai pengganti minyak tanah, inovasi nasi empok, tiwul pengganti beras dan wajib memakai bahan bekas yang ramah lingkungan, (e) perangsang minat regenerasi budaya - untuk 
mencapai hal ini maka Even Malang Kembali wajib terlebih dahulu memprioritaskan serta mengutamakan penampilan seniman, budayawan, budaya serta tradisi asli daerah untuk memberikan penghargaan dan kesempatan seluas-luasnya para penerus budaya tradisi, dan penyajian maupun penyampaian hasil penelitian serta pembelajaran kearifan lokal pada kalayak umum, (f) media hiburan yang edukatif - untuk mencapai hal ini Even Malang Kembali mewajibkan setiap peserta Panggung Rakyat pada setiap malam hari selama kegiatan berlangsung, harus menanpilkan panggung hiburan untuk rakyat dan pada siang hari diwajibkan untuk melakukan kegiatan worshop seperti kegiatan worshop wayang kulit, wayang orang, wayang beber, ludruk, ketoprak, macapat dan pengunjung tidak dipungut biaya atau gratis, sehingga para pengunjung terhibur dan memperoleh edukasi, (g) memupuk rasa kepedulian sosial - setiap tahun pada saat berlangsungnya perhelatan akbar Even Malang Kembali ada sekitar 300-an pengunjung yang datang dari luar Kota Malang maupun luar negri. Para pengunjung diwajibkan untuk berpakaian ala malang tempoe doeloe, pakaian adat setempat, sehingga hal ini membuat sesama pengunjung merasa sama, menghilangkan sekat strata sosial semua merasa sama, sehingga even tersebut sebagai media praktis untuk menumbuh-kembangkan rasa kepedulian sosial serta menghilangkan sekat-sekat strata sosial, (h) membangun image pariwisata - untuk mencapai hal ini, maka Even Malang Kembali memperkenalkan serta menyuguhkan aneka ragam acara budaya yang berbasis tradisi, sehingga hal ini merupakan modal dasar untuk membumikan image daerah di dunia pariwisata yang sehat, edukatif, menyejahterakan masyarakat dengan citra pariwisaata - the old festival Malang Kembali berbasis bangunan "Cagar Budaya" dan (i) menyumbang Pendapan Asli Daerah - dampak multiplier effect Even Malang Kembali di bidang pariwisata akan menjadi penyumbang devisa daerah yang sangat signifikan di masa depan - dan hal ini berdampak langsung pada kesejahteraan masyarakat.

5. Pengemasan Stand Pamer Even Malang Kembali. Untuk terlasananya berbagai tujuan kegiatan tersebut yang telah dirumuskan tersebut di atas, maka ditatalah stand-stand pamer kegiatan, yaitu mencakup (a) Stand pamer hasil-hasil kerajinan rakyat - Stand pamer ini berbasis tradisi nama-mama pasar dan ditata serta ditempatkan di sepanjang trotoar Jalan Besar Ijen. Nama-nama stand pamer yaitu stand pamer Pasar Pon, Pasar Pahing, Pasar Kliwon, Pasar Wage dan stand Pasar Legi (b) Stand panggung hiburan rakyat mencakup nama-nama panggung kesenian tradisonal yaitu stand Panggung Ludruk, Panggung Keroncong, Panggung Worshop, Panggung Topeng Monyet, Panggung Perpustakaan Umum, Panggung Griya Telkomsel, dan Panggung Diorama Aktifitas (Brosur Even Malang Kembali 2006, 2007 dan 2008).

Untuk menunjang pelaksanaan kegiatan dan menhindari campur tangan dari pihak lain dan agar penyelenggaraan Even 
Malang Kembali tidak melenceng dari tujuan awal serta berbasis bangunan "Cagar Budaya" dan mengedepankan wawasan pelestarian untuk keejahteraan masyarakat, maka kegiatan Even Malang Kembali silesenggarakan oleh sebuah badan yang berbadan hukum yaitu Yayasan Inggil. Yayasan ini memiliki hak paten serta hak cipta untuk mengatur model penyelenggaraan Even Malang Kembali berbasis "Cagar Budaya", berwawasan pelestarian Cagar Budaya untuk menyejahterakan masyarakat.

Kegiatan Even Malang Kembali, tidak hanya berhenti pada perhelatan akbar, manun agar hal-hal yang telah disajikan dalam Even Malang Kembali membumi pada setiap sanubari masyarakat pecinta Cagar Budaya di Kota Malang, maka Yayasan Inggil (Inggil Documentary - Rumah Makan Inggil ) mengabadikan dokomen-dokumen penting berwa-wasan sejarah, pelestarian serta edukasi tersebut dengan mendirikan Museum Malang Tempoe Doeloe, di Jl.Gadjah Mada No.5, tidak jauh dari kompleks Aloen-aloen Bundar serta Balai Kota Malang dan bersebelahan dengan Rumah Makan Inggil.

Tata pamer Musium Malang Tempoe Doeloe antara lain mencakup Ruang Tata Pamer Malang pada Masa Prasejarah, Ruang Tata Pamer Ekskavasi Arkeologi, Ruang Tata Pamer Malang pada Masa Hindhu-Buddha dari masa Kerajaan Kanjuruan hingga Majapahit Ahkir, Ruang Tata Pamer Peralatan Rumah Tangga, Ruang Tata Pamer Berdirinya Kotapraja Malang, Ruang Tata Pamer Masa Pendudukan Jepang, Ruang Tata Pamer Para Bupati Kabupaten Malang serta para pejabat Wali Kota Kotapraja Malang, Ruang Tata Pamer Malang Bumi-Hangus, dan Ruang Tata Pamer Masa Perjuangan Bangsa Indonesia di Malang dalam Rangka Mepertahankan Kemedekaan Indonesia. Selain itu juga terdapat Ruang Tata Pamer Kegiatan Even Malang Kembali, ruang edukasi untuk permainan anak- anak, dan untuk kegiatan worshop batik maupun topeng (Brosur Museum Malang Tempoe Doeloe).

Untuk mengenali lebih jauh bangunanbangunan "Cagar Buadya" Indiis serta sentrasentra kerajinan rakyat di Kotapraja Malang, Yayasan Inggil - Inggil Documentary menerbitkan buku tentang sejarah berdirinya gedunggedung perkantoran pemerintahan, bank, gedung sekolah, rumah ibadah, kompleks pertokoan dan lanskap Kotapraja Malang disertai nama-nama jalan masa Pemerintahan Hindia-Belanda. Urain buku disertai dengan foto asli, peta dan uraian nilai-nilai arsitektur serta nilai-nilai sejarah maupun nilai penanda jaman bangunan dalam kaitannya dengan Lintasan Sejarah Kotapraja Malang. Penyusunan buku dikemas dengan model Guide Book Pariwisata, sehingga buku guide book tersebut diberi judul Malang, Telusuri Dengan Hati, penyusunnya adalah Cahoyo (2007) penggagas Even Malang Kembali.

Dari urain tersebut di atas maka, diketahui bahwa perhelatan akbar Even Malang Kembali dapat dijadikan salah satu model pemanfataan "Cagar Budaya" untuk kesejahteraan masyarakat. Model pemanfaatan Cagar Budaya untuk kesejateraan masyarakat tersebut dapat dikembangkan serta disebarluaskan ke beberapa daerah di Indonesia sebagai salah satu model pemanfaatan Cagar Budaya berwawasan pelestarian untuk kesejahteraan masyarakat. Dengan demikian lambat-laut akan dapat menggugah hati masyarakat untuk terlibat lansung melestarikan bangunan-bangunan "Cagar Budaya" untuk kepentingan kesejakteraan masyarakat .

\section{PENUTUP}

Berpijak pada uraian singkat penyelenggaraan Even Malang Kembali berbasis pelestarian bangunan "Cagar Budaya" : Bangunanbangunan Indis tersebut di atas, maka kegiatan Even Malang Kembali dapat dijadikan model 
pemanfaataan "Cagar Buadya" untuk kesejahteraan masyarakat (Ardika,I.G. 2012: 2230). Melalui uraian tersebut model pemanfaatan "Cagar Budaya" untuk kesejakteraan masyarakat, didahului dengan kajian ilmiah yang berkaitan dengan nilai-nilai ksejarahan, nilai-nilai arsitektur bangunan-bangunan penanda jaman dan berkaitan langsung dengan proses perjalanan sejarah suatu daerah atau kota, contohnya Lintasan Sejarah Kotapraja Malang (Suprapta, 2008:27-30).

Setelah langkah tersebut, nilai-nilai yang terkandung dalam bangunan cagar budaya dikemas berbasis pelestarian dengan cara merefitalisasi tradisi yang terkait dengan perjalanan sejarah suatu daerah atau kota dan masih berlanjut hingga masa sekarang. Untuk hal ini maka Even Malang Kembali dikemas untuk memberi kesempatan seluas-luasnya kepada seniman serta budayawan, para pengrajin tradisional, para pencinta tradisi kebudayaan untuk tampil maksimal di ajang Even Malang Kembali. Disamping itu juga melibatkan seluruh elemen masyarakat berbasis pelestarian cagar budaya untuk membangunan image pariwisata budaya berbasis "Bangunan Cagar Budaya" (Ardika, 2012: 22-25)

Agar kegiatan Even Malang Kembali yang berbasis pada kegiatan pelestraian bangunan "Cagar Budaya", tidak mudah dilupakan oleh masyarakat, maka perlunya membangun museum lintasan sejarah daerah atau kota seperti halnya Museum Malang Tempoe Doeloe yang didirikan oleh Yayasan Inggil. Untuk menumbuh kembangkan image pariwisata budaya berbasis bangunan "Cagar Budaya" perlunya menerbitkan goide book pariwisata yang terkait langsung dengan lintasan sejarah suatu daerah atau kota seperti halnya Goide Book : Malang Telususri Dengan Hati yang diterbitkkan oleh Yayasan Inggil: Inggil Documentary. Apabila tahap-tahap tersebut di atas dijalankan, maka lambat-laun akan tertaman suatu kesadaran pada masyarakat bahwa bangunan "Cagar Budaya" tidak dianggap sebagai "benda mati"serta tidak bernilai, melainkan dapat digunakan sebagai sarana untuk kesejahteraan masyarakat, sehingga masyarakat akan ikut terlibat langsung dalam kegiatan pelestarian bangunan-bangunan "Cagar Budaya" untuk membangun image pariwisata budaya yang dapat menyejahterakan masyarakat (U.U. Cagar Budaya No.11, Tahun 2010 : Bagian Keempat).

\section{DAFTAR PUSTAKA}

Anonim, 2014, Undang-Undang Republik Indonesia Nomor 11 Tahun 2010, Jakarta: Kementrian Kebudayaan dan Pariwisata, Direktorat Jenderal Sejarah dan Purbakala

Ardika, I.G., 2012, "Pariwisata Minat Khusus Berbasis Arkeologi" dalam Arkeologi Untuk Publik, hlm 22 - 32, Jakarta: Ikatan Ahli Arkeologi Indonesia

Soekiman,D. 2000. Kebudayaan Indis dan Gaya Hidp Msayarakat Pendukungnya di Jawa (Abad XVII Medio Abad XX), Yogyakarta: Yayasan Bentang Budaya

Cahoyo, D. 2007. Malang Telusuri Dengan Hati, Malang: Inggil Documentary

Satrio, J.A. 2012, "Perlindungan Warisan Budaya Daerah Menurut UndangUndang Cagar Budaya" dalam Arkeologi Untuk Publik, hlm.1521, Jakarta: Ikatan Ahli Arkeologi Indonesia.

Kartasasmita, C.B dan Kartasasmita.B., 1979, Khasanah Pengetahuan Bagi Anak-Anak :Angkutan, (seri terjemahan), Jakarta: Tira Pustaka

Liempt, F.J.M.v, 1939. Stadsgemeente Malang 1914-1939, Surabaya: Gedrukt Bij N.V.G. Kolff \& Co. 
Marzuki,L.H. 2012, "Potensi Arkeologi Kawasan Bangunan Indis di Kota Gorontalo" dalam Arkeologi Untuk Publik, hlm.240 - 254, Jakarta: Ikatan Ahli Arkeologi Indonesia.

Pemerintah Kabupaten Daerah Tingkat II Malang, 1984. Dari Pura Kānjuruahan Menuju Kabupaten Malang : Tinjauan Sejarah Hari Jadi Kabupaten Malang (tidak terbit), Malang: Pemerintah Kabupaten Daerah II Malang.

Suprapta, B. 2008, “ Kilas Balik Lintasan Sejarah di Kawasan Dataran Tinggi Malang: Masa Prasejarah Hingga Akhir Masa Kerajaan Sinhasari" dalam Seabad Kebangkitan Nasional: Perubahan dan Kesinambungan dalam Sejarah Indonesia, Malang: Cakrawala Indonesia Jurusan Sejarah FS-UM

Team Sejarah IKIP-Malang, 1976. Perkembangan Kabupaten Malang Sejak Jaman Purba Sampai Dengan Pelita I : Tijauan Dari Segi Politik, Ekonomis, Sosial dan Budaya, (tidak terbit) Malang: Pemerintah Kabupaten Daerah Tingkat II Kabupaten Malang 